\title{
INVESTIGAÇÃO DO SOLVATOCROMISMO E IONOCROMISMO DO CORANTE AZUL DO NILO ATRAVÉS DAS ESPECTROSCOPIAS RAMAN, INFRAVERMELHO E UV-VIS
}

\author{
Michele Lemos de Souza ${ }^{a, *,(0)}$ e Paola Corio ${ }^{\mathrm{b}}$ \\ aDepartamento de Química, Universidade Federal Fluminense, 27213-145 Volta Redonda - RJ, Brasil \\ bDepartamento de Química Fundamental, Universidade de São Paulo, 05513-970 São Paulo - SP, Brasil
}

Recebido em 28/05/2019; aceito em 22/08/2019; publicado na web em 23/10/2019

\begin{abstract}
SOLVATOCHROMISM AND IONOCHROMISM OF THE NILE BLUE DYE A THROUGH RAMAN, INFRARED AND UVVIS SPECTROSCOPIES. The present work presents the systematic study of Nile Blue A (NB) dye, a cationic textile dye, through electronic and vibrational spectroscopies (Raman, resonant Raman scatter and infrared absorption) in the presence of distinct anions (chloride, bromide, perchlorate and sulfate) and protic and aprotic solvents of different polarities (water, ethanol, acetone, acetonitrile, chloroform and ethyl acetate). There were vibrational changes resulting from the formation and destruction of aggregates according to the chemical environment, besides the formation of a molecular conformation with higher energy in apolar aprotic solvents.
\end{abstract}

Keywords: Nile blue; solvatochromism; Raman spectroscopy; infrared spectroscopy.

\section{INTRODUÇÃO}

Corantes pertencentes à classe das benzo(a)fenoxazinas são amplamente empregados como sensores biológicos e sensores de $\mathrm{pH}$, além de apresentarem alto rendimento quântico e intensa fluorescência, o que os fazem interessantes para aplicações como sensibilizadores e fotossensibilizadores, por exemplo. ${ }^{1-5}$ Essa classe de corantes advém da fusão lateral entre uma estrutura 2,4-oxazina (anel de seis membros heterosubstituído por um nitrogênio e um oxigênio respectivamente) e dois anéis aromáticos, resultando em uma estrutura similar à um antraceno. Um terceiro anel aromático é fundido à face do carbono $\alpha$ desta estrutura, chamada de face a, formando a então benzo(a)fenoxazina. O corante azul do Nilo (do inglês Nile Blue A, NB, Figura 1) é um corante catiônico pertencente à classe das benzo(a)fenoxazinas, apresentando radicais amina (C-NRR") e imino (RR'C=NR"), podendo ser chamado então de benzo(a)fenoxazinium. Esse corante é encontrado comumente na forma de sais de cloreto e sulfato, e mais raramente como sais de perclorato. Foi reportado pela primeira vez por Möhlau e Uhlmann em 1896, e ainda recentemente é bastante empregado como corante têxtil e marcador biológico. ${ }^{6,7}$<smiles>CCN(CC)c1ccc2nc3c4ccccc4c(=[NH2+])cc-3oc2c1</smiles>

Figura 1. Fórmula estrutural do corante $N B$

Uma característica físico-química importante de alguns corantes é a capacidade de agregação, afetando suas propriedades fotoquímicas e colorimétricas. Corantes iônicos tendem a formar agregados em soluções diluídas, levando à formação de dímeros (agregados simples), e algumas vezes outros agregados ainda maiores. ${ }^{8-12}$ Nesses casos, a natureza molecular do agregado é fortemente afetada por parâmetros como concentração, estrutura

*e-mail: micheleusp@gmail.com molecular do corante, força iônica do meio, temperatura e presença de solventes orgânicos. ${ }^{7} \mathrm{O}$ corante NB, por exemplo, apresenta capacidade de formar agregados $\mathrm{H}$ em solução aquosa, que estabiliza sua estrutura. ${ }^{13-15}$ Esse conjunto molecular apresenta transferência de carga intermolecular de alta energia. ${ }^{16,17}$ Embora cada corante possua características intrínsecas, algumas regras são de uso geral para a agregação deste tipo de composto. Em geral, a agregação é fortemente afetada pelo aumento da temperatura, pelo aumento da concentração do corante, da força iônica do meio e pela adição de solventes orgânicos apolares, devido à forte interação hidrofóbica dos agregados em solução aquosa. ${ }^{7}$ Essa classe de corante tem sido amplamente empregada como marcadores biológicos, contudo, a literatura nessa área apresenta carência em estudos vibracionais do comportamento relacionado à agregação e ao solvatocromismo.

A aplicação de técnicas espectroscópicas vibracionais na investigação de diferentes espécies químicas de relevância ambiental, biológica, na construção civil e em patrimônio histórico-cultural tem crescido significantemente nos últimos anos, pois são técnicas que apresentam elevada sensibilidade e não necessitam de grande quantidade amostra. Como exemplos recentes, o emprego da microscopia Raman na identificação de minerais em rochas, ${ }^{18}$ na análise de pele humana associada à quimiometria para estudo da ação de produtos de cuidados pessoais, ${ }^{19}$ na caracterização de cimento preparado a partir do reuso de escória de alto forno, ${ }^{20}$ na identificação de microplásticos poluentes de ambientes aquáticos e águas minerais, ${ }^{21}$ na determinação da penetração de corantes em camadas protetoras de óxido de alumínio poroso, ${ }^{22}$ etc. As análises empregando a espectroscopia Raman são rápidas, não necessitam de preparação de amostra e apresentam um espectro característico para cada substância, sendo chamada de impressão digital da molécula. Mesmo em situações em que ocorre a mistura de espécies, ferramentas matemáticas como quimiometria têm demostrado grande potencialidade para a identificação de espécies em matrizes complexas. A espectroscopia Raman também tem se firmado como uma técnica útil na identificação de diversos compostos orgânicos, visto que fornece informações importantes sobre a estrutura molecular e não sofre interferência de meio aquoso. ${ }^{23,24}$ No presente trabalho foram realizadas análises por espectroscopias eletrônica e vibracionais (Raman e infravermelho) de um sistema contendo o corante têxtil catiônico NB e ânions de diferentes características químicas (haletos e oxiânions) e solventes próticos e apróticos de 
distintas polaridades com o intuito de verificar alterações vibracionais devido à sua suscetibilidade de formação/destruição de agregados.

\section{PARTE EXPERIMENTAL}

\section{Materiais, equipamentos e reagentes}

Os espectros vibracionais foram obtidos em um espectrômetro Micro-Raman Renishaw System 3000, com detector do tipo CCD (charge coupled device), resolução espectral de $4 \mathrm{~cm}^{-1}$, acoplado a um microscópio Olympus BTH-2 e equipado com uma objetiva com aumento de 50×, em laser He-Ne (Spectra Physic, modelo 127), radiação em $632,8 \mathrm{~nm}$; e $\mathrm{Ar}^{+}$com radiação em 457,5 nm; para a coleta dos espectros infravermelhos (IR) foi empregado um espectrômetro FT-IR Bomen, e um pastilhador $\mathrm{KBr}$. Os espectros eletrônicos foram obtidos em um espectrofotômetro Shimadzu UV-3101 PC, duplo feixe, com lâmpada de halogênio (infravermelho próximo e visível) e de deutério (ultravioleta), equipado com detectores do tipo fotomultiplicadora (ultravioleta e visível) e cela de $\mathrm{PbS}$ (infravermelho próximo).

Os reagentes utilizados (corante Azul do Nilo de pureza $\geq 75 \%$, sais cloreto, brometo, perclorato e sulfato de potássio de pureza $>99 \%$ ) foram adquiridos da empresa Sigma-Aldrich, os solventes empregados (água, etanol, acetonitrila, acetona, clorofórmio e acetato de etila, todos em graus P.A.) foram adquiridos da empresa Merck. Todos os materiais foram utilizados sem purificação prévia.

\section{Preparação de amostras}

\section{Efeito ionocrômico}

Analisou-se o comportamento do NB em solução aquosa $1,0 \times 10^{-5} \mathrm{~mol} \mathrm{~L}^{-1}$, sob agitação constante na presença dos sais de cloreto, brometo, perclorato e sulfato de potássio $\left(0,1 \mathrm{~mol} \mathrm{~L}^{-1}\right)$ através da adição da quantidade de sal calculada diretamente em recipiente contendo a solução aquosa de NB. A temperatura durante os ensaios foi mantida a $23{ }^{\circ} \mathrm{C}$ com banho termostático. Após cerca de $2 \mathrm{~h}$ de interação entre as soluções aquosas contendo NB e o sal de interesse, as soluções aquosas foram secas em um dessecador sob vácuo e os espectros IR e Raman foram obtidos dos sólidos resultantes. Os espectros eletrônicos foram obtidos em solução aquosa em função do tempo de interação.

\section{Efeito solvatocrômico}

Analisou-se o comportamento do corante NB em concentração $1,0 \times 10^{-4} \mathrm{~mol} \mathrm{~L}^{-1}$ e $1,0 \times 10^{-5} \mathrm{~mol} \mathrm{~L}^{-1}$ em água deionizada e $1,0 \times 10^{-5} \mathrm{~mol} \mathrm{~L}^{-1}$ em solventes com diferentes polaridades (água, etanol, acetona, acetonitrila, clorofórmio e acetato de etila). Após a preparação da solução de NB nos solventes apolares de interesse, foi realizada a extração com água deionizada utilizando um funil de separação. Foram adicionados $25 \mathrm{~mL}$ do solvente orgânico contendo o NB solubilizado e duas alíquotas de $20 \mathrm{~mL}$ de água deionizada. As soluções orgânicas foram secas por sulfato de magnésio antes da obtenção dos espectros eletrônicos UV-Vis. Espectros IR e Raman em diferentes radiações excitantes foram obtidos do sólido resultante da rotoevaporação das fases orgânicas e secagem das fases aquosas coletadas.

\section{RESULTADOS E DISCUSSÃO}

\section{Monômeros, dímeros e ionocromismo}

Na Figura 2 estão dispostos os espectros UV-Vis do NB em duas concentrações distintas. A literatura indica que corantes iônicos são termodinamicamente capazes de formar dímeros, sendo observada nos espectros eletrônicos da molécula em solução aquosa a alteração do comprimento de onda da banda com máxima absorção em função da temperatura. ${ }^{10,14,17}$ Sendo o NB um corante benzo(a)fenoxazinico iônico, este corante é passível de sofrer agregação do tipo $\mathrm{H} \cdot{ }^{16} \mathrm{O}$ aparecimento de um ponto isosbéstico na Figura 2 indica que há a presença de duas espécies (o monômero e o dímero) em equilíbrio. ${ }^{17}$ De acordo com a literatura, a banda com máximo de absorção em 635 nm está relacionada ao monômero do NB, enquanto que a banda em $591 \mathrm{~nm}$ está relacionada ao seu dímero. Verificam-se nos espectros eletrônicos de ambas as concentrações analisadas $\left(1,0 \times 10^{-4} \mathrm{~mol} \mathrm{~L}^{-1}\right.$ e $1,0 \times 10^{-5} \mathrm{~mol} \mathrm{~L}^{-1}$ ), apresentados na Figura 2, bandas de absorção do dímero e do monômero. Visto que se trata de um equilíbrio entre as espécies, a alteração das intensidades relativas entre os máximos e a banda associada aos agregados são justificados pelo aumento da concentração do corante NB. Em maiores concentrações ocorre o aumento da intensidade da banda em $591 \mathrm{~nm}$, sugerindo o aumento o número de dímeros ou agregados moleculares em solução.

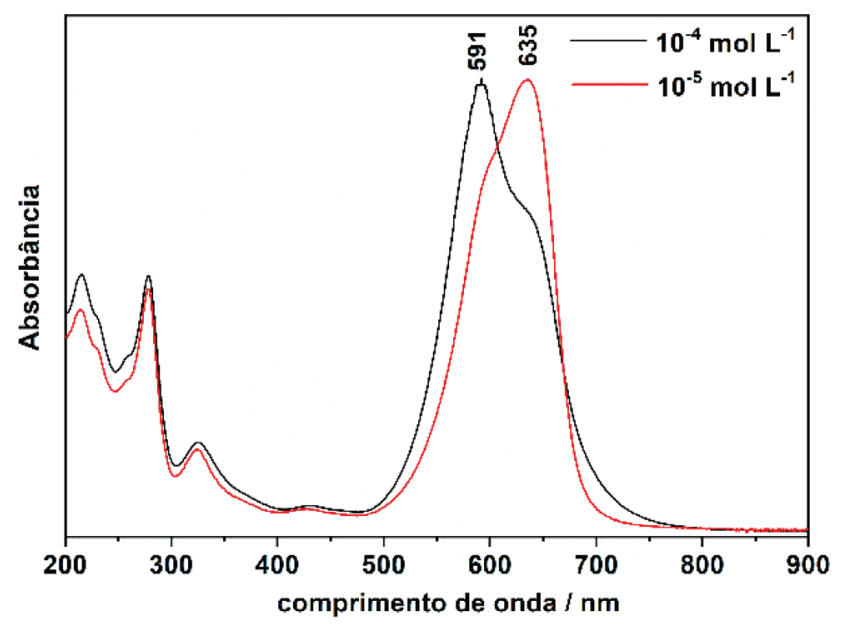

Figura 2. Espectros UV-Vis de NB em solução aquosa nas concentrações $1,0 \times 10^{-4} \mathrm{~mol} \mathrm{~L}^{-1}$ e $1,0 \times 10^{-5} \mathrm{~mol} \mathrm{L^{-1 }}$

Sais de cloreto, brometo, perclorato e persulfato foram adicionados à solução $1,0 \times 10^{-5} \mathrm{~mol} \mathrm{~L}^{-1}$ do corante NB. A presença em alta concentração dos distintos ânions causou a diminuição da banda de absorção do monômero em função do tempo quando comparado ao ensaio em água deionizada (Figura 3 (A)-(E)). A solução aquosa de NB não apresenta alterações mesmo após 240 minutos, contudo soluções contendo os íons sulfato e perclorato (oxiânions) $0,1 \mathrm{~mol} \mathrm{~L}^{-1}$ sofreram uma diminuição da banda de absorção em $635 \mathrm{~nm}$ em função do tempo, sendo possível observar a formação de um precipitado (sólido particulado de coloração azul), e as soluções contendo íons brometo e cloreto (haletos) sofreram uma diminuição da banda em $635 \mathrm{~nm}$ e houve o surgimento de uma banda de absorção em 510 e $504 \mathrm{~nm}$ respectivamente, seguido da precipitação de um sólido particulado de coloração rósea.

Por se tratar de um corante catiônico, suas interações intermoleculares em solução podem ser afetadas em função da força iônica da solução. É possível observar na Figura 3 um comportamento diferenciado da molécula na presença de oxiânions e haletos. A adição de íons sulfato e perclorato na concentração de $0,1 \mathrm{~mol} \mathrm{~L}^{-1}$ aumentou a força iônica do meio que exibiu efeito de "salting out" para o corante, diminuiu a solubilidade do monômero em água induzindo a precipitação do corante NB (precipitado azul).

Os sais de haletos $\left(\mathrm{Cl}^{-}\right.$e $\left.\mathrm{Br}^{-}\right)$, por sua vez, apresentam ânions pequenos, pouco polarizáveis. Sua adição causou alteração lenta na solubilidade dos monômetros e dímeros, formando uma terceira estrutura com absorbância em menores comprimentos de onda (504 nm 

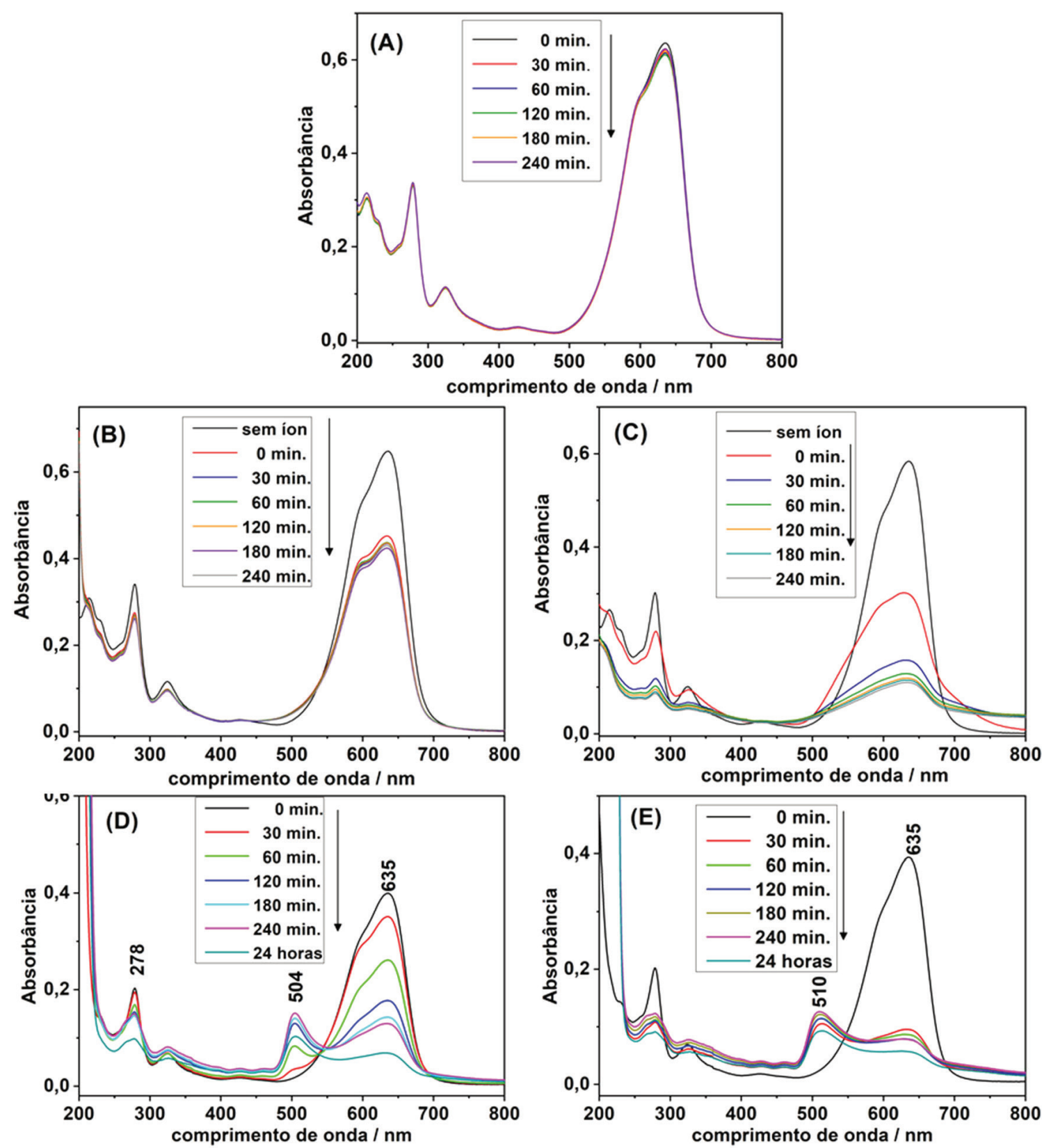

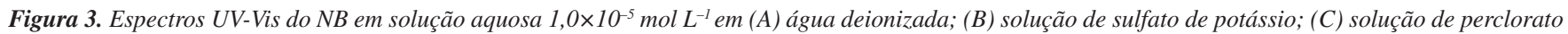
de potássio; (D) solução de cloreto de potássio; (E) em solução de brometo de potássio; (concentração final das soluções iônicas 0,1 mol $L^{-1}$ )

e $510 \mathrm{~nm}$ ). Após um longo período (maior que $24 \mathrm{~h}$ ), ocorreu a formação de precipitados de coloração rósea. A formação desse terceiro composto de estado eletrônico de maior energia alterou o equilíbrio monômero/dímero, levando ao consumo de ambos e à diminuição da intensidade das bandas em 591 e $635 \mathrm{~nm}$.

\section{Efeito da polaridade do solvente}

O efeito da polaridade do solvente é pertinente para descrever interações intermoleculares entre agregados e solventes. A criação de microambientes de um conjunto de moléculas de solvente pode alterar os estados de energia eletrônica e vibracional do corante para a formação dos agregados. ${ }^{17}$ Os espectros eletrônicos do corante NB dissolvido em diversos solventes orgânicos estão apresentados na Figura 4.

As polaridades relativas e os índices de refração dos solventes estão apresentados na Tabela 1. De acordo com os dados da polaridade

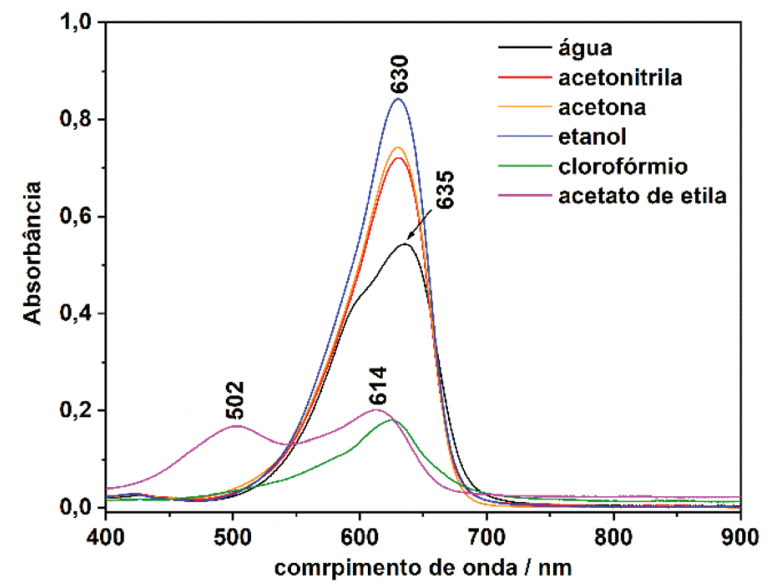

Figura 4. Espectros eletrônicos do NB nos solventes indicados (concentração $1,0 \times 10^{-5} \mathrm{~mol} \mathrm{~L}^{-1}$ ) 
relativa apresentada na literatura, essa é crescente a partir da acetona, acetonitrila, clorofórmio, etanol, acetato de etila e água. ${ }^{25}$ No entanto, considerar o acetato de etila como um solvente de alta polaridade pode levantar certa desconfiança, uma vez que ele é um solvente orgânico com considerável número de carbonos saturados. Outras divergências, como considerar a acetona altamente apolar, por exemplo, também estão presentes na Tabela 1.

Tabela 1. Polaridades relativas e índices de refração à $25^{\circ} \mathrm{C}$ para os solventes empregados

\begin{tabular}{ccc}
\hline Solvente & Polaridade Relativa $^{25}$ & $\begin{array}{c}\text { Índice de refração } \\
\left(\mathrm{a} 25^{\circ} \mathrm{C}\right)^{26}\end{array}$ \\
\hline Água & 1,000 & 1,332 \\
Acetato de Etila & 0,894 & 1,370 \\
Acetona & 0,355 & 1,357 \\
Acetonitrila & 0,460 & 1,342 \\
Clorofórmio & 0,800 & 1,444 \\
Etanol & 0,789 & 1,359 \\
\hline
\end{tabular}

Uma abordagem considerando o índice de refração dos solventes cujas grandezas têm uma relação de caráter aproximadamente inverso à polaridade, porém considerando massa molar e densidade, conforme a equação de Claussius-Mossotti para determinação da polarização molar, também pode ser averiguada. Neste caso, a ordem crescente das polarizações calculadas a partir dos índices de refração são: água, acetonitrila, etanol, acetona, clorofórmio e acetato de etila. ${ }^{26} \mathrm{~A}$ ordem crescente de polarização molar (ordem decrescente de polaridade molecular) está de acordo com o esperado, sendo os solventes mais polares a água, acetonitrila, etanol e acetona, enquanto que os menos polares são clorofórmio e acetato de etila. A equação de ClaussiusMossotti, dependente do índice de refração, é utilizada quando não há contribuição do dipolo elétrico permanente na polarização devido à característica apolar das moléculas, por exemplo. Sendo assim, para considerações envolvendo moléculas apolares, a abordagem segundo o índice de refração é mais pertinente que a abordagem segundo a polaridade relativa.

Os espectros eletrônicos em solução de acetonitrila, etanol e acetona (solventes de polarização intermediária, conforme Tabela 1) apresentaram comportamentos semelhantes, com máximo de absorbância em $630 \mathrm{~nm}$ (deslocamento hipsocrônico da banda mais intensa em relação à solução aquosa) e a ausência de ombros. Tais solventes apresentam maior polarização que a água, e estabilizam a formação
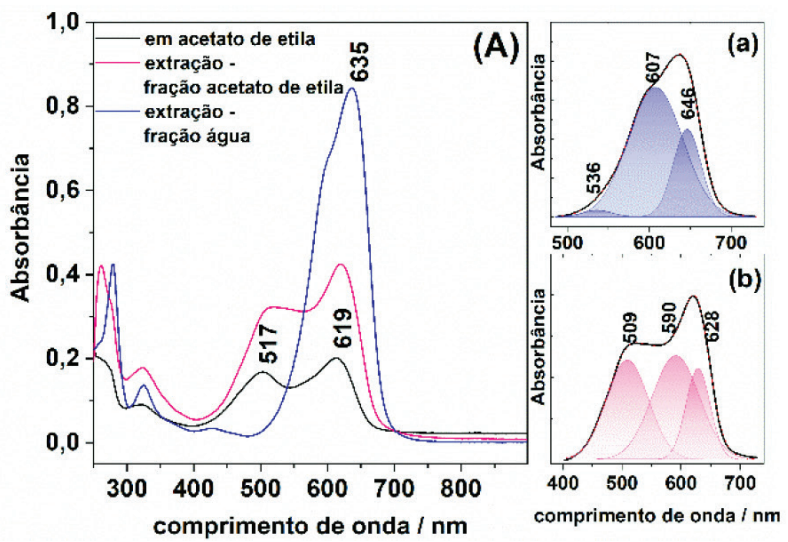

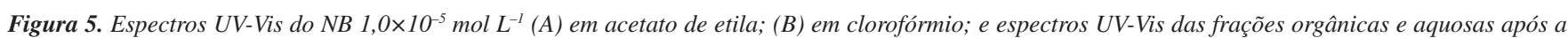
extração por polaridade. Decomposição de bandas (a) da fração aquosa de extração com acetato de etila; (b) da fração orgânica da extração com acetato de etila; (c) da fração aquosa de extração com clorofórmio; (d) da fração orgânica da extração com clorofórmio preferencial do monômero. O espectro eletrônico do composto em solução aquosa, ou seja, solvente de maior polaridade (e menor polarização), apresentou duas bandas inicialmente atribuídas ao equilíbrio entre o monômero e o dímero, conforme apresentado na Figura 2.

Em solvente aprótico de menor polaridade, porém, de alta polarização, como o clorofórmio, por exemplo, também é notada a banda em $630 \mathrm{~nm}$, além de um ombro em comprimentos de onda menores, contudo, com uma absorbância significativamente menor devido à baixa solubilidade do composto nesse meio, chegando à saturação quando adicionamos a massa respectiva à concentração $1,0 \times 10^{-5} \mathrm{~mol} \mathrm{~L}^{-1}$. Em acetato de etila, cuja polarização é maior que para o clorofórmio (conforme Tabela 1 e discussão acima), nota-se o surgimento de uma banda relativamente intensa em $502 \mathrm{~nm}$ e o deslocamento hipsocrômico da banda em 635 para $614 \mathrm{~nm}$. O composto apresenta maior solubilidade nesse solvente e, consequentemente, maior absorbância.

A solubilização em solventes de polarização intermediária insomente a banda com absorbância em $630 \mathrm{~nm}$. Essa situação corresponde à maior estabilidade termodinâmica dos monômeros, uma vez que estes solventes são polarizáveis e podem estabilizar o cátion do corante isoladamente. Neste caso, a polarização desses solventes não é suficientemente alta para provocar a formação dos agregados e nem suficientemente baixa (como a água) para formar os dímeros.

Para NB em solventes como acetato de etila e clorofórmio, apresentados na Figura 5 (A) e (B) respectivamente, foram realizadas extrações com água, permitindo a análise dos espectros UV-Vis independente das fases orgânica e aquosa (Figura 5 (a)-(d)). A solubilização do NB em solventes alifático e clorado, cujas polaridades são substancialmente menores que nos demais solventes utilizados, causou a estabilidade de uma estrutura de maior energia de transição intermolecular. De acordo com a literatura, esse comportamento em solventes alifáticos e clorados provém da torção do grupo amina terciária mantendo a molécula de NB planar. ${ }^{7}$ Essa conformação estrutural é altamente energética e apresenta transição eletrônica referente à transferência de carga intermolecular de alta energia (517 nm).

$\mathrm{Na}$ Figura 5(A) o espectro UV-Vis do NB em acetato de etila (linha preta) apresenta dois máximos de absorção: em aproximadamente 517 e $619 \mathrm{~nm}$. Os espectros das duas fases após a extração com água esclarecem a extração de moléculas de NB de menor energia para a fase aquosa e a presença do composto de maior energia em fase orgânica em um equilíbrio de solubilização nas duas fases. Na fase aquosa (fase que apresentou coloração azul e está representada no espectro UV-Vis pela linha azul) o NB apresentou espectro UV-Vis semelhante e tão intenso quanto ao apresentado na Figura 2 de

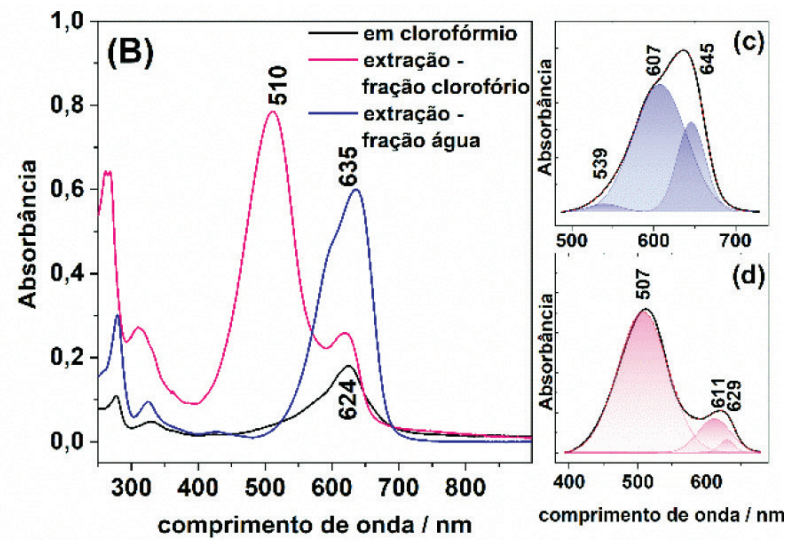
fluenciou na não agregação das moléculas do corante NB mantendo 
concentração $1,0 \times 10^{-5} \mathrm{~mol} \mathrm{~L}{ }^{-1}$, em que havia maior quantidade de monômeros; na fase orgânica (fase que apresentou coloração rósea e está representada no espectro UV-Vis pela linha rosa) os espectros UV-Vis apresentam as mesmas bandas observadas inicialmente no acetato de etila, porém, apresentando uma intensidade maior. Dessa forma, verifica-se que a torção do grupo amina que dá origem à estrutura estável no solvente orgânico é um processo reversível.

Os espectros nas Figura 5(a) e (b) apresentam a decomposição de bandas da fase aquosa e fase orgânica da interação entre o NB e acetato de etila. Nota-se as posições distintas dos máximos para ambas as fases, indicando a presença de espécies distintas.

Na Figura 5(B) está apresentado o espectro da solução de NB em clorofórmio (linha preta), com absorbância máxima em 624 nm e baixa intensidade. Após a extração com água, e analisados os espectros da fase aquosa e da fase orgânica, ficam evidentes a presença de bandas distintas entre as duas fases devido ao equilíbrio de solubilização do NB. Na fase aquosa (de coloração azul e está representada pela linha azul) foi obtido o espectro de NB sem alterações e na fase orgânica (de coloração rósea e está representado pela linha rosa) ocorreu o surgimento de uma banda bastante intensa com máximo em 510 nm. Nas Figura 5 (c) e (d) estão apresentadas as decomposições de bandas dos espectros em fase aquosa e em fase orgânica após a extração. Assim, como observado para o solvente acetato de etila, em clorofórmio ocorre a formação de um composto mais energético, com transições eletrônicas distintas dos monômeros e dos dímeros de NB.

Para ambos os ensaios, a fase orgânica Figura 5 (b) e (d) apresenta bandas decompostas na região atribuída aos monômeros em $628 \mathrm{~nm}$, aos dímeros em aproximadamente $590 \mathrm{~nm}$ e uma banda com transição em maiores frequências, com máximo em aproximadamente 509 nm, que não está relacionada ao equilíbrio dímero/monômero. A análise vibracional do composto formado na fase orgânica foi realizada.

\section{Análise vibracional}

O corante NB apresenta o efeito Raman Ressonante (RR) quando excitado em 632,8 nm, conforme apresentado na Figura 6. Nesse espectro nota-se que a banda em $590 \mathrm{~cm}^{-1}$ tem intensidade relativa aumentada em relação aos espectros obtidos fora de ressonância (em $1064 \mathrm{~nm}$ ) e em pré-ressonância (457,5 nm). Essa banda, além de apresentar alteração na intensidade relativa devido ao efeito de intensificação RR, também está deslocada para maiores frequências de acordo com o aumento da energia de excitação. Esse comportamento dispersivo é bastante interessante, e pode ser relacionado aos diferentes espectros eletrônicos observados entre o monômero (banda de absorção em aproximadamente $635 \mathrm{~nm}$, ou seja, em condição de ressonância) e o dímero (banda de absorção em $590 \mathrm{~nm}$, fora da condição de ressonância). ${ }^{27} \mathrm{~A}$ banda em $1637 \mathrm{~cm}^{-1}$ (sob excitação em $632,8 \mathrm{~nm}$ ) mantém intensidade relativa às demais bandas em outras energia de excitação, porém apresenta deslocamento considerável nas três radiações excitantes (quanto menor a energia de excitação, maior o número de onda). No entanto, verifica-se que com excitação em $1064 \mathrm{~nm}$ são obtidas mais informações vibracionais que quando excitado em $632,8 \mathrm{~nm}$.

Após a interação do corante NB com os íons cloreto e brometo ocorreu a formação de precipitado róseo, enquanto que da interação com os íons sulfato e perclorato ocorreu a formação de um precipitado azul. Os sólidos foram coletados por catação e deixados em dessecador sob vácuo por 6 horas. No ensaio do efeito da polaridade do solvente, após a extração observou-se uma solução rósea na fase orgânica e a formação de precipitado róseo muito particulado após um tempo maior que $24 \mathrm{~h}$. A fração orgânica foi rotoevaporada até restar somente o sólido róseo, e deixado no dessecador sob vácuo por 3 horas.

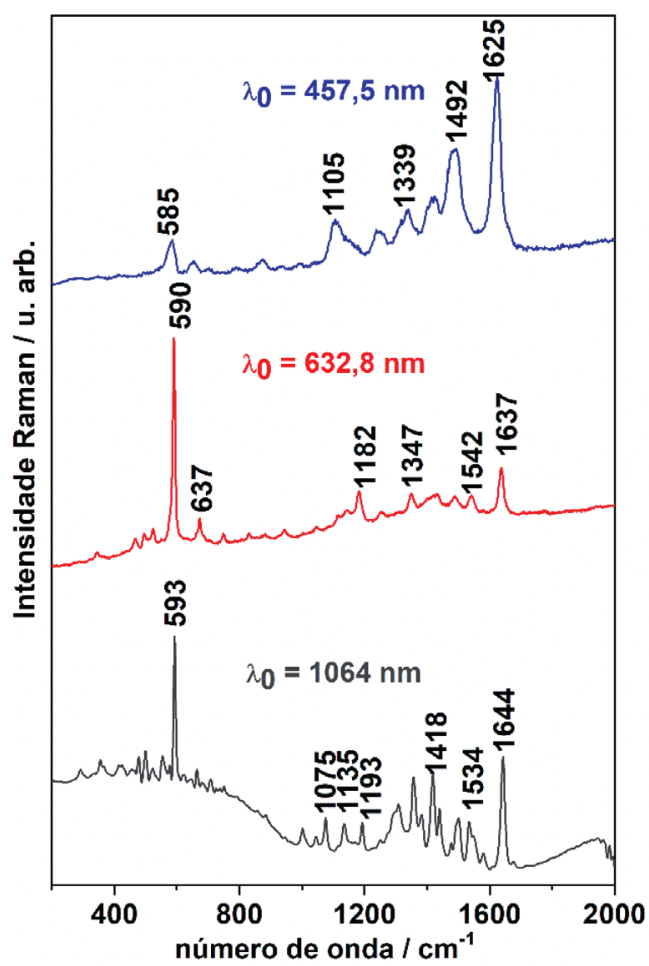

Figura 6. Espectros Raman e Raman Ressonante do corante NB sólido em radiações excitantes $457,5 \mathrm{~nm}, 632,8 \mathrm{~nm}$ e $1064 \mathrm{~nm}$

Os compostos sólidos foram analisados conforme apresentamos na Figura 7.

Em uma análise qualitativa, embora os sólidos formados pelo

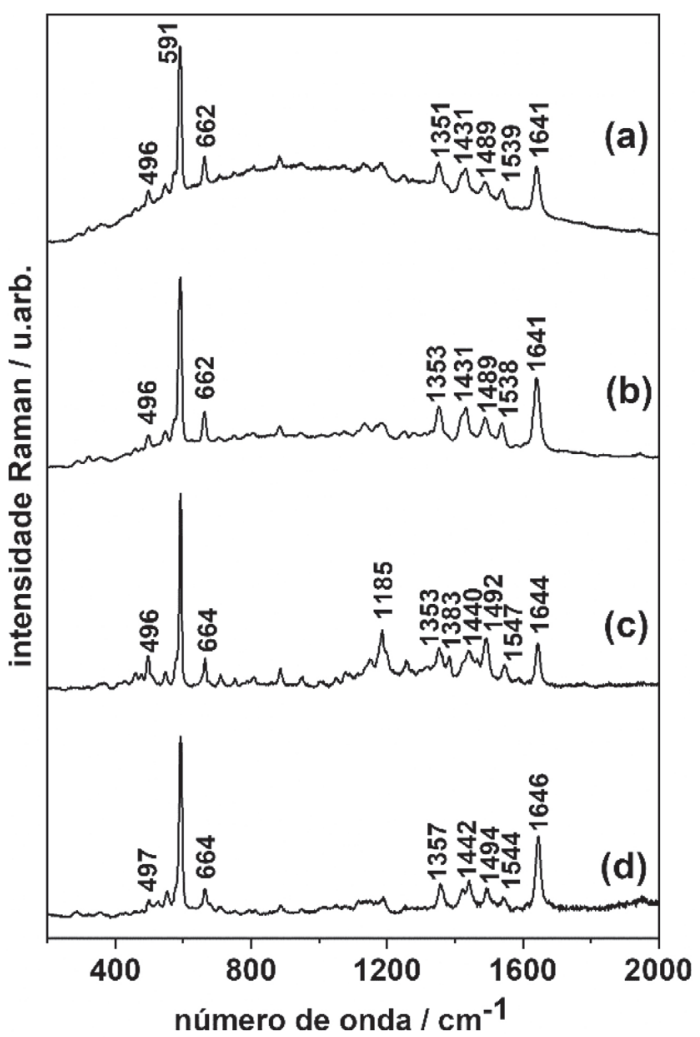

Figura 7. Espectros Raman dos precipitados secos (a) após 5 h de interação em $\mathrm{K}_{2} \mathrm{SO}_{4} 0,1 \mathrm{~mol} \mathrm{~L}^{-1}$; (b) após 5 h de interação em $\mathrm{KCl} \mathrm{0,1} \mathrm{mol} \mathrm{L} \mathrm{L}^{-1}$; (c) após a extração por polaridade acetato de etila:água (fração acetato de etila); (d) $N B$ sólido (sem alterações); $\lambda_{0}=632,8 \mathrm{~nm}$ 
ensaio da força iônica tenham apresentado coloração diferenciada (azul para oxiânion e róseo para haletos, respectivamente), após sua secagem a coloração apresentada para ambos voltou a ser azul. Foi possível observar que nos espectros das Figura 7 (a) e (b) não houve diferenciação em relação ao NB sem modificações (Figura 7(d)). Sendo assim, após a secagem os compostos obtidos permanecem o próprio NB de menor energia.

Após a evaporação da fase orgânica obtida pela extração em acetato de etila foi obtido um sólido que se manteve róseo. $\mathrm{Na}$ Figura 7(c) observa-se o surgimento de um conjunto de bandas em aproximadamente $1185 \mathrm{~cm}^{-1}$ e uma banda em $1383 \mathrm{~cm}^{-1}$ em relação ao NB puro (Figura 7(d)), sugerindo que, mesmo na ausência de solvente, o composto é estável.

A comparação entre os espectros dos compostos em pastilha de $\mathrm{KBr}$ (NB puro, e dos compostos obtidos após a interação com meio apresentando força iônica alterada e dos compostos obtidos após interação com acetato de etila) apresentou mudanças em algumas bandas, conforme apresentado nos espectros da Figura 8.

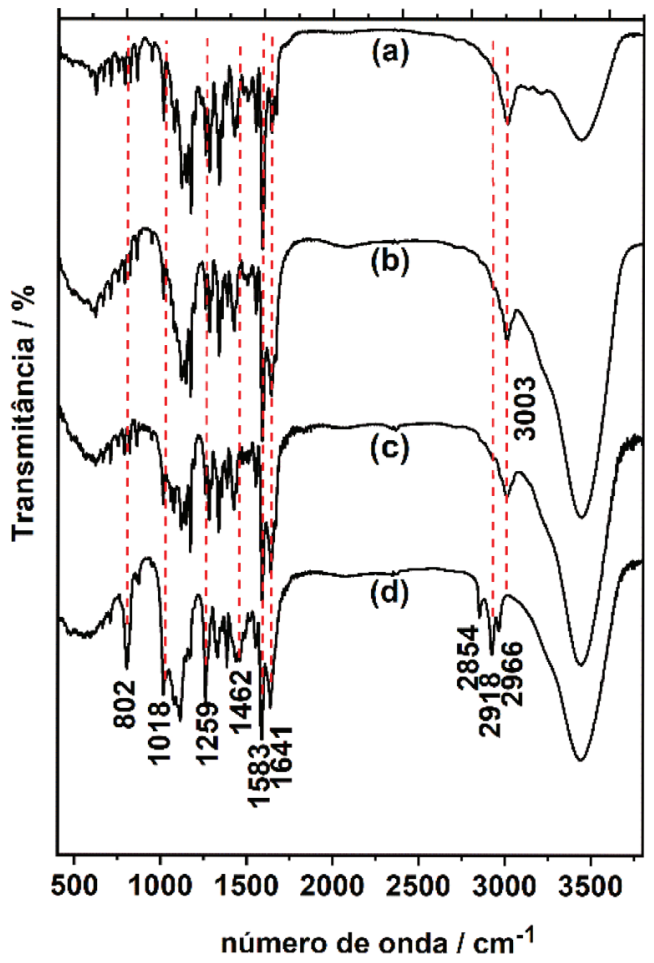

Figura 8. Espectros FT-IR do NB em pastilhas de $\mathrm{KBr}($ a) puro; (b) sólido após interagir em solução de $\mathrm{KBr}$; (c) sólido resultante da fração aquosa após interagir com acetato de etila; (d) sólido resultante da fração orgânica após interagir com acetato de etila

Os espectros do sólido, após interagir com $\mathrm{KBr}$, e da fase aquosa, após interagir com acetato de etila (Figura 8(b) e (c) respectivamente), não apresentaram distinções em relação ao NB puro (Figura 8 (a)), correspondendo, portanto, à mesma espécie molecular do corante NB. A Figura 8 (d), no entanto, apresenta aumento da intensidade das bandas na região entre $1018 \mathrm{~cm}^{-1}$ e $1259 \mathrm{~cm}^{-1}$, resultando em um alargamento das bandas. Ainda na Figura 8(d), o surgimento de três bandas em alta frequência é nítido $\left(2854,2918\right.$ e $\left.2966 \mathrm{~cm}^{-1}\right)$. A banda em $3003 \mathrm{~cm}^{-1}$ não está presente na Figura 8(d). A possibilidade de se tratar de traços de solvente é aceitável, pois o acetato de etila, por sua vez, apresenta bandas de $\mathrm{CH}$ alifático nesta região. No entanto, as bandas do solvente nesta região estão consideravelmente deslocadas em relação ao espectro IR obtido. Por outro lado, considerando a torção do grupamento amina terciária do corante $\mathrm{NB}$, os grupos radicais etila podem apresentar estiramentos $\mathrm{CH}_{3}$ fora do plano do conjunto benzo(a)fenoxazínico e desimpedidos estericamente e, portanto, seus modos de vibração podem estar intensificados em relação à configuração para a formação de dímeros, por exemplo. Sendo o acetato de etila um solvente aprótico pouco polar, a molécula de NB não sofre protonação ou desprotonação quando nesse solvente. No entanto, a forma iônica tampouco é solúvel nesse meio e, portanto, uma estrutura ou complexo molecular deve respeitar as condições de solubilidade para se manter estável neste meio.

Na Tabela 2 são apresentadas atribuições tentativas para algumas bandas do NB puro e o produto da interação em acetato de etila.

Tabela 2. Atribuições tentativas para os principais modos vibracionais por absorção no infravermelho do NB puro e do produto da interação em acetato de etila ${ }^{28,29}$

\begin{tabular}{ccc}
\hline NB puro & $\begin{array}{c}\text { NB após interação com } \\
\text { acetato de etila }\end{array}$ & Atribuições \\
\hline 3009 & - & $v(\mathrm{NH})$ \\
1640 & 1638 & $\left(\mathrm{NH}_{2}\right)$ \\
1588 & 1587 & $v(\mathrm{C}=\mathrm{C})+\left(\mathrm{NH}_{2}\right)$ \\
1549 & 1550 & $v(\mathrm{C}=\mathrm{C})+\left(\mathrm{NH}_{2}\right)$ \\
1439 & 1435 & $\delta(\mathrm{C}-\mathrm{H})+\left(\mathrm{CH}_{2}\right)$ \\
1384 & 1384 & $\delta(\mathrm{CH})$ \\
1335 & - & $v(\mathrm{C}=\mathrm{C})+\delta(\mathrm{C}-\mathrm{H})+\rho\left(\mathrm{CH}_{2}\right)$ \\
803 & 802 & $\mathrm{v}(\mathrm{N}-\mathrm{C})($ amina terciária $)$ \\
\hline
\end{tabular}

$\delta$ - deformação angular; $v$ - estiramento; $\rho$ - rocking.

A molécula de NB (Figura 1) possui um grupo amina terciária com dois radicais etila e um grupo amina primária catiônico, ambos ligados ao grupo cromóforo fenozaxínico. A amina terciária e a amina primária são grupos doador e aceptor de elétrons respectivamente. $\mathrm{O}$ grupo amina terciária, por sua vez, pode girar em seu eixo de ligação sigma ligado ao grupo cromóforo, formando a configuração onde os grupamentos etila estão torcidos, referente ao plano da molécula (ou seja, perpendiculares ao plano), ou paralelos ao plano da molécula com os grupamentos etila apresentando o primeiro carbono no plano da molécula e o segundo fora do plano. Quando os grupamentos etila estão torcidos referente ao plano da molécula ocorre então a hibridização dos estados eletrônicos das aminas doador/aceptor, promovendo a transferência de carga intramolecular sob excitação em baixas energias, monômeros. A literatura indica que essa rotação na posição torcida ao grupo benzo(a)fenoxazínico aumenta o momento de dipolo da molécula, tornando-a mais estável em solventes polares, e a transferência de carga intramolecular mais pronunciada neste estado que em seu estado planar (radicais etila no plano do grupo benzo(a)fenoxazínico). ${ }^{30} \mathrm{Na}$ configuração em que os grupamentos etila estão no plano da molécula é possível que uma segunda molécula se aproxime de modo que o grupo aceptor e o grupo doador apresentem interação intermolecular, formando dímeros. O aumento da concentração permite que estas configurações, cuja conversão para a forma planar ocorre rapidamente, formem os dímeros e adquiram estabilidade.

Quando, após rotação da ligação $\mathrm{C}-\mathrm{N}$, os radicais etila se encontram paralelos ao plano da molécula, sua polaridade é diminuída e estabilizada em solventes de menor polaridade. A estrutura planar apresenta transição eletrônica intramolecular mais energética, resultando no aparecimento da banda de absorção em menores comprimentos de onda, uma vez que as bandas HOMO e LUMO se tornam mais distantes nessa configuração. . $^{730}$

A análise dos espectros infravermelho corrobora com a suposição acima, visto que ocorre a intensificação da banda em $802 \mathrm{~cm}^{-1}$ e em 
$2854,2918,2966 \mathrm{~cm}^{-1}$ emergentes no espectro da interação do NB em acetato de etila apresentam atribuições referentes à amina terciária e os estiramentos $\mathrm{CH}$ de cadeia alifática insaturada, respectivamente, que na estrutura planar se encontram mais pronunciados que na estrutura torcida, devido à não formação de dímeros.

\section{CONCLUSÕES}

O espectro UV-Vis da solução aquosa de NB, concentração $1,0 \times 10^{-5} \mathrm{~mol} \mathrm{~L}^{-1}$ apresentou duas bandas de absorção e um ponto isosbéstico, indicando o equilíbrio entre o dímero e o monômero de NB. Conforme a concentração é aumentada, ocorre a inversão dos máximos para menores comprimentos de onda, sugerindo que a formação de dímeros eleva o estado energético da molécula. A análise de adição de ânions em solução de NB, causando a alteração da força iônica, demonstrou que a presença de haletos permite a formação de um composto de maior energia de transição eletrônica que resultava em um precipitado róseo. Após a secagem, o sólido retorna à coloração azul. Na presença de oxiânios ocorre somente a diminuição da banda de maior absorbância, seguido da formação de cristais de NB devido ao efeito "salting-out".

Em solventes mais apolares clorados e alifáticos (clorofórmio e acetato de etila) foi observada a formação de um composto de maior energia de transição. A extração por diferença de polaridade diminuiu a concentração do NB na fase orgânica e permitiu a conclusão de um processo reversível. De acordo com a literatura, foi concluído que há a formação de moléculas planares de baixa estabilidade em solvente orgânico, de coloração rósea. Tal composto foi analisado pelas espectroscopias FT-IR e Raman, contudo, a espectroscopia FTIR evidenciou a formação do composto planar de grupamento amina livre devido à intensificação da banda em $803 \mathrm{~cm}^{-1}$.

\section{AGRADECIMENTOS}

As autoras agradecem o apoio da FAPESP (2008/03636-5 e 2016/21070-5), da Capes e do CNPq (Universal 407447/2016-4).

\section{REFERÊNCIAS}

1. Liu, W.; Sun, R.; Ge, J. F.; Xu, Y. J.; Xu, Y.; Lu, J. M.; Itoh, I.; Ihara, M.; Anal. Chem. 2013, 85, 7419.

2. Santra, M.; Jun, Y. W.; Reo, Y. J.; Sarkar, S.; Ahn, K. H.; Pigment 2017, $142,161$.

3. Frade, V. H. J.; Coutinho, P. J. G.; Moura, J. C. V. P.; Goncalves, M. S. T.; Tetrahedron 2007, 63, 1654.
4. Zhan, Y.-H.; Li, X.-J.; Sun, R.; Xu, Y.-J.; Ge, J.-F.; Anal. Chim. Acta 2016, 933, 175.

5. Basu, S.; Panigrahi, S.; Praharaj, S.; J. Phys. Chem. A 2007, 111, 4, 578.

6. Rama, B.; Naik, R. S.; Coutinho, P. J. G.; Gonçalves M. S. T.; Dyes Pigm. 2013, 99, 220.

7. Martinez, V.; Henary, M.; Chem. - Eur. J. 2016, 22, 13764.

8. Antonov, L.; Gergov, G.; Petrov, V.; Kubista, M.; Nygren, J.; Talanta 1999, 49, 99.

9. Steinhurst, D. A.; Owrutsky, J. C.; J. Phys. Chem. B 2001, 105, 3062.

10. Evdokimov, I. N.; Eliseev, N. Y.; Akhmetov, B. R.; J. Pet. Sci. Eng. 2003, $37,145$.

11. Sun, G.; Zhao, Y.; Lang, W.; J. Chem. Theory Comput. 2015, 11, 2257.

12. Chakraborty, A.; Adhikari, R.; Saha, S. K.; J. Mol. Liq. 2011, 164, 250.

13. Goftar, M. K.; Moradi, K.; Kor, N. M.; Eur. J. Exp. Biol. 2014, 4, 72.

14. Nasr, C.; Hotchandani, S.; Chem. Mater. 2000, 12, 1529.

15. Pereira, R. V.; Gehlen, M. H.; Spectrochim. Acta, Part A 2005, 61, 2926.

16. Eisfeld, A.; Briggs, J. S.; Chem. Phys. 2006, 324, 376.

17. Niazi, A.; Yazdanipour, A.; Ghasemi, J.; Kubista, M.; Spectrochim. Acta, Part A 2006, 65, 73 .

18. Santos, A.; Menezes, D.; Ellena, J.; Andrade, M.; Quim. Nova 2019, 42, 489.

19. Hancewicz, T. M.; Xiao, C.; Zhang, S.; Misra, M.; Appl. Spectrosc. 2013, 67, 1463.

20. Mikhailova, O.; del Campo, A.; Rovnanik, P.; Fernández, J. F.; TorresCarrasco, M.; Cem. Concr. Compos. 2019, 99, 32.

21. Sobhani, Z.; Al Amin, M.; Naidu, R.; Megharaj, M.; Fang, C.; Anal. Chim. Acta 2019, 1077, 191.

22. Matijo, T.; Asadauskas, S. J.; Bikul, G.; Selskis, A.; Jankauskas, S.; Vi, J.; Color. Technol. 2019, 135, 275.

23. Kahouli, K.; Hajji, R.; Abdelbaky, M. S. M.; García-granda, S.; Chaabouni, S.; J. Mol. Struct. 2019, 1195, 641.

24. Issaoui, F.; Amamou, W.; Bekri, M.; Zouari, F.; Dhahri, E.; Valente, M. A.; J. Mol. Struct. 2019, 1189, 175.

25. Reinchardt, C.; Solvents and Solvent Effects in Organic Chemistry, $3^{\mathrm{a}}$ ed., Wiley-VCH FmbH \& Co. KGaA: Weinheim, 2002.

26. Smallwood, I.; Handbook of Organic Solvent Properties, $1^{\text {a }}$ ed., Butterworth-Heinemann: Oxford, 2012.

27. Bar, J.; Monezi; N. M.; Ando, R. A.; J. Raman Spectrosc. 2018, 49, 230.

28. Schelereth, D. D.; Karykin, A. A.; J. Eletroanal. Chem. 1995, 395, 221.

29. Krikak, M.; Murtagh, M. T.; Shahriari, M. R.; J. Sol-Gel Sci. Technol. 1997, 10, 153;

30. Guido, C. A.; Mennucci, B.; Jacquemin, D.; Adamo, C.; Phys. Chem. Chem. Phys. 2010, 12, 8016.

FAPESP contribuiu para custear a publicação deste artigo. 